Challenging or consolidating neoliberalism: Prominent discursive traces on a university-level citizenship course

\author{
Abdulkerim Sen \\ College of Education, Eskisehir Osmangazi University, Eskisehir, Turkey \\ Email: akerimsen@gmail.com
}

Word Count of Anonymous Manuscript: 6998 


\title{
Challenging or consolidating neoliberalism: Prominent discursive traces on a university-level citizenship education course
}

\author{
Citizenship education (CE) has become popular with various descriptors at \\ different levels of education. In higher education, it has gained status with the \\ title of global CE (GCE). Although the ways of delivery of GCE vary within and \\ across universities, research suggests that the prevailing ideology of \\ neoliberalism that promotes a notion of de-contextualised and individualistic \\ citizenship seeps into all forms of GCE. Therefore, attempts have been made to \\ strengthen alternative conceptualisations of GCE that challenge inequalities and \\ facilitate the participation of marginalised identities. This study reports on the \\ curriculum development of an alternative form of GCE underpinned by the \\ theories of cosmopolitan citizenship. Empirical evidence (interviews, observation \\ notes, evaluation data and other course materials) is drawn from three iterations \\ of a GCE course taken by 124 students at a Russell Group university in the UK \\ from 2016 to 2018. The study concludes that the prevalence of neoliberal GCE \\ may be effectively challenged by recognising the significance of collective action \\ and integrating a strong practical dimension to the curriculum.
}

Keywords: global citizenship education; internationalisation of higher education; neoliberalism; cosmopolitanism; commercialisation of higher education.

\section{Introduction}

Global citizenship education (GCE) has now gained status in higher education institutions (HEIs) around the world (Horey, Fortune, Nicolacopoulos, Kashima, \& Mathisen, 2018). Many universities offer GCE through discrete courses (Clifford \& Montgomery, 2014; Hammond \& Keating, 2018; Harris, 2010; Papadiamantaki, 2014), extra-curricular activities, student mobility programs and the promotion of intercultural dialogue within and beyond university campuses (Caruana, 2014; Green, 2018; Li, 2017; McCowan, 2012). Some researchers emphasised that the surge of interest in GCE is an effect of the internationalisation of HEIs, which is a comprehensive process of the integration of international elements into the nationalist frame of HEIs (Leask, 2015). 
Others explained the rise of interest in GCE by highlighting that the current world problems (global warming, international terror, mass migrations, global poverty etc) create an urgent need to promote a global perspective since the members of global society are in need of solidarity more than ever (Green, 2018; Rizvi, 2009). Researchers within this group underlined that the nationalist way of thinking that was traditionally promoted in HEIs is not holding a great promise for developing solutions to the global issues, so young people must now embrace a global mindset that would facilitate intercultural solidarity and dialogue necessary to tackle global problems.

In explaining the popularity of GCE, a third group of researchers devoted attention to the prevalence of neo-liberalism as universities now operate in the market economy in which they are pressurised to offer courses in order to attract more 'customers' (Andreotti, 2011; Clifford \& Montgomery, 2017; Marshall, 2011). This perspective is supported by well-founded observations that GCE programmes have an explicit concern to develop students' knowledge and skills demanded by global market economy in which people of diverse backgrounds meet for transactional relations (Camicia \& Franklin, 2011; Hammond \& Keating, 2018; Pashby \& Andreotti, 2016).

Given that the neoliberal GCE represents the dominant form, some liberal or critical-oriented educators have attempted to conceptualise alternative forms of GCE that serve to the ideal of building an equal and just global society. As will be laid out in greater detail in the following section, the key difference between the two forms is that neoliberal GCE aims to make young people competent in intercultural communication for economic reasons, whereas the alternative conceptualisations of GCE reject that instrumental-economic rationality by recognising the intrinsic value of intercultural encounter. This conceptual distinction theoretically frames the present research, which reports from a case of developing and implementing an alternative form of GCE. 
Having been taught since 2016, the citizenship course under investigation was part of an intense-two-week long summer programme at a Russell Group university in the UK.

Since the course was taught in a paid UK university in which neoliberal influences were prominent, this article is focused on revealing how the course in question was influenced by neoliberal, liberal and critical discourses. It explores whether or not the implemented curriculum, which is underpinned by the theories of cosmopolitan citizenship and human rights perspectives, was effective to minimise neoliberal and maximise liberal and critical discourses.

\section{Developing a frame for analysis}

The theories of citizenship education (CE) are often classified into two groups in a way that one of these groups is cast positive and the other, negative. While the positive is often labelled with descriptors like active, global, critical, transformative, multicultural, cosmopolitan, democratic, strong, thick, maximalist and radical, the negative is called minimalist, weak, soft, apolitical, passive, traditional, nationalist and individualistic (e.g. Banks, 2011; Biesta, 2011; Johnson \& Morris, 2012; McLaughlin, 1992; Osler \& Starkey, 2003). Arguing that the binary conceptualisations are reductionist, Oxley and Morris (2013) classified the different global citizenship (GC) conceptions into two main categories: cosmopolitan and advocacy types. This attempt not to cast either of these categories as the positive blur the boundaries between them as one may wonder what prevents those who embrace cosmopolitan-individualistic ideologies from taking an activist-advocacy position. Dichotomous classifications may indeed appear reductionist from a theoretical perspective, but they may be useful from a practical point of view. When we ignore the hegemony of neoliberalism, we may end up with an amalgam of classifications. However, when we evaluate GCE in its real-life context, the prominent feature of GCE theories may highlight a position in relation to neoliberalism. 
Neoliberalism differs considerably from classical liberalism in that the latter defends a minimal government control in market relations, whereas the former recognises the state as the promoter of market relations (Harvey, 2005; Olssen, 1996). For McChesney (1999), neoliberalism 'refers to the policies and processes whereby a relative handful of private interests are permitted to control as much as possible of social life in order to maximize their personal profit' (p. 7). McChesney (1999) furthers this poignant definition arguing that neoliberalism aggravates socio-economic inequalities and gives birth to 'a depoliticised citizenry marked by apathy and cynicism' (p. 10). While liberal democracy thrives in communities whose members meet in 'libraries, public schools, neighbourhood organizations, cooperatives, public meeting places, voluntary associations and trade unions', neoliberalism creates an impoverished culture of consumerism in which people come together in 'shopping malls' (p. 11).

Forcing to construe the world through the prism of economic-instrumental rationality, neoliberalism sets the goal of education as raising entrepreneurial and competitive individuals who are educated to maximise their profits in the marketplace. In fact, the promotion of commodification and commercialisation in neoliberal systems reduces the political concept of democracy to 'an economic concept' by crippling the power of non-market civic, public, social, communal, and political values essential to the functioning of liberal democracies (Apple, 2006). From the 1980s onwards, the spread of neoliberalism has diminished the social rights dimension of citizenship (Biesta, 2011). Even the term active citizenship may be regarded as neoliberal wording of citizenship as it brings to the fore an individualistic notion that side-lines the communal, contextual and structural dimensions of citizenship. It exalts individual success, individual responsibility and individual choice with a supposition that individual faults are the root-cause of socio-economic and political ills. 
Public and higher education sectors have not remained unaffected from the fast spread of neoliberalism which is facilitated by advancements in communication and transportation technologies (Apple, 2006; Giroux, 2002; Marginson, 2014). In western liberal democracies, universities were regarded as civic spaces where intellectuals worked to imagine alternative visions for society. In neoliberal democracies, universities have become subordinated to the wishes of corporate bodies where the hiring of academics, funding of research and admission of students are all decided by taking into account the market imperatives (Giroux, 2014). Acting as a business-like sector, universities now sell what they know to individuals and corporations, which results in the shrinking of space for humanities and other areas that do not produce a market value. That neoliberal orientation manifests itself in the growing adoption of quantified performance measures for evaluating success and university ranking tables.

Signifying the backbone of neoliberal higher education culture, economicinstrumental rationality corrupts the very core intellectual space of liberal democracy in which ideas are refined to improve the public good. Its intrusion into universities deprives academics of the ability to decide over their own intellectual activities (Giroux, 2014). As a result, disadvantaged identities who are not likely to afford tuition fees and do profitable jobs, such as sexual minorities, women, disabled, non-white, diverse ethnic and racial identities, get marginalised in HEIs. Giroux (2002) identifies the major risks that neo-liberalisation of higher education poses for the future of democracy:

...higher education cannot be viewed merely as sites for commercial investment or for affirming a notion of the private good based on exclusively on the fulfilment of individual needs. Reducing higher education to the handmaiden of corporate culture works against the critical social imperative of educating citizens who can sustain and develop inclusive democratic public spheres (p. 432). 
In such settings, market imperatives favour research and teaching that are likely to yield profitable outcomes at a minimum cost. Substance and form of scientific activities get heavily affected by the demands and dictates of economically powerful actors, people and corporations. GCE programmes can hardly advance civic capacities of liberal universities to educate citizens that would maintain democracy and imagine alternative visions for society. They are not likely to transform the entrenched civic values of young people who pay for their education in the hope that they will find profitable jobs after graduation. The intrinsic professional commitment that can foster high-minded values of a democratic civic culture may get completely vanished in this picture.

The differences between neoliberal and alternative forms of GCE are elaborated in several studies (e.g. Camicia \& Franklin, 2011; Caruana, 2014; Clifford \& Montgomery, 2014; Li, 2017; Marshall, 2011). For example, Shultz (2007) identified two alternative forms. The first, radical GCE views globalisation as a mask for western domination and promotes international solidarity and activism against the domination of wealthy elites. The second, transformationalist GCE encourages learners to recognise the complexities of the global economic system, make students feel belonging to the common humanity. Although Shultz (2007) does not employ the term human rights, the distinction between the radical and the transformationalist GCEs can be enhanced by associating the latter with a human rights perspective.

Rizvi (2009) developed an alternative GCE conceptualisation drawing on the theories of cosmopolitan citizenship, which is significant since the course under investigation incorporated influences from cosmopolitanism. While the theory of education for cosmopolitan citizenship has been strengthened notably by Osler \& Starkey (2003), Rizvi (2009)'s endeavour is more relevant here since it strengthens the basis of cosmopolitan learning in the context of university-level CE and addresses the 
corrosive influences of neoliberalism. In his view, GCE underpinned by classical cosmopolitanism emphasises universal ethics, human rights, social justice principles and promote a humanistic vision of how to live together in pluralist societies by moving beyond the differentiating nation-state narratives of self, rights and citizenship.

In order to evaluate the quality of GCE programmes, Shultz (2011) suggests looking at intercultural and structural dimensions. A weak intercultural dimension indicates that the programme considers intercultural dialogue instrumental to the market. A weak structural dimension means that the programme pays inadequate attention to socio-political issues of context it is implemented. Interculturally and structurally strong programmes are transformative in that they give due regard to both local/national and global issues and promote activism and campaigning to bring about a positive change in structures that produce inequalities.

GCE programmes may incorporate a varying combination of three discursive orientations: neoliberal, liberal and critical (Pashby \& Andreotti, 2016). Constituting three dimensions of a 'social cartography' (Andreotti, Stein, Pashby, \& Nicolson, 2016, p. 86), the neoliberal interface views the university as 'accountable to the market' in which 'knowledge, research, teaching and service are commodified' (Pashby \& Andreotti, 2016, pp. 776-777). The liberal interface views the university as a civic site for educating "national citizens who will contribute to the future progress and development of society' (p. 777). The critical dimension sees the university as an elite space of power struggle which needs to be democratised by giving equal voice to the powerless if it is to promote GC.

This article seeks an answer to the following question: What sources of influences can be identified in the content and outcome of the citizenship course in question? It problematizes the extent to which the course in question was successful at 
minimising the impact of neoliberal discourses and maximising the impact of liberal and critical discourses. After identifying the sources of prominent influences, I discuss whether or not the reliance on cosmopolitan citizenship theories was an effective way to teach an ethical notion of GC in a university setting where neoliberal discourses are prevalent. Overall, this paper reflects on the experience of teaching a citizenship course for three consecutive years in a major western university in an effort to make critical suggestions for increasing the effectiveness of the positive version of GCE.

\section{Methodology}

Action research puts theory and practice in constant interaction with the goal of improving conditions for human flourishing (Brydon-Miller, Greenwood, \& Maguire, 2003). It is an apt design for this investigation since the course teaching team, of which the author was a part, met regularly beforehand and every day during the course was underway to improve the curriculum. The course was offered as a strand of a broader GCE programme at a university, which hosted a diverse student population of nearly 39000 students (UCL, 2018a). Taken by both undergraduate and postgraduate students, this non-credit and free course lasted two weeks before the end of summer terms.

The formal structure of the curriculum included a taught element and a group project. In the taught part, experts from universities and campaigning organisations gave lectures and organised workshops about active citizenship and strategies of effective campaigning. In the group project part, students teamed up, went to NGOs they had been placed and made attempts to contribute to an ongoing campaign of their NGO or start a new campaign relevant to their NGOs' focus. The group projects provided students with an opportunity for experiential and collaborative learning by requiring them to work in groups and produce tangible outcomes like short films, posters or presentations. Students were asked to post their reflections on social media, start an 
online campaign and comment on each other's posts. Students were also offered a whole-day training on how to shoot a short-film via mobile phones. In-between the morning sessions and NGO placements, students attended debriefings where they discussed their progress with a navigator whose research was related to CE. In the end, all short films went into a competition, and the winner was displayed at the final ceremony of the GCE programme. The expected learning outcomes of the course are specified on the course website as follows:

Through developing your campaigning skills, you will be able to explore ways through which citizen power can produce change for social justice; protection, promotion and fulfilment of human rights; and environmental sustainability. You will be able to develop strategic thinking, communication skills and networking.

$$
\text { (...) }
$$

By the end of the programme you are expected to contribute to the campaigning, lobbying, awareness raising work done by various organisations, you are also encouraged to document your journey and experience through tweeting, blogging and engaging in various social media outlets (UCL, 2017).

Empirical evidence for the study is drawn from three iterations of the course from 2016 to 2018 , involving 124 students. The number of students who took the course was 38 in 2016, 43 in 2017 and 43 in 2018. Data sources include observation notes, semistructured interviews with voluntary students, course evaluation data and other course materials like course handbooks and course-related content on the university website. To note, the permission of the university's research ethics committee was secured in relation to the fully anonymous use of the course evaluation data on the condition that no potentially contentious comment is made.

Data analysis was a deductive process guided by the categories identified in the literature (Andreotti et al., 2016; Pashby \& Andreotti, 2016). In order to use both qualitative and quantitative evidence, I adopted a combination of critical discourse 
analysis (CDA) and content analysis approach (Fairclough, 2010; Krippendorff, 2004). I drew on the conventions of CDA in a descriptive rather than analytical level in identifying neoliberal, liberal and critical discourses permeated the course content and outcomes. I looked for evidence to show the influence of the three discourses and used statistical evidence in a supportive manner. Excerpts from the data sources were chosen on the basis of the degree to which they represented the discourse in question. To ensure trustworthiness, the relevant specifics of the course were described, and the findings were supported by multiple data sources (Merriam, 2009). I shared the draft of this article with the members of the teaching team and received critical comments which helped me to find plausible explanations for certain complications that came up in the analysis. In this way, I was able to elaborate and strengthen the initial findings.

This study is delimited by the unavailability of data on students' understanding of GC before they took the course. Although my observation notes highlight the international configuration of students who took the course, there was no data on the demographics of the cohorts evaluated, which prevented me from making comparisons along the lines of gender, year of study, degree and so on. It also prevented the calculation of the percentages of students who expressed neoliberal, liberal and critical discourses. In addition, the unconventional features of the course (e.g. timing of the course, its non-credit bearing) posed challenges to drawing generalizable conclusions in terms of curriculum development. For these reasons, this study is designed more like an informed reflection on the three-year-long experience of teaching a university-level citizenship course. Therefore, the findings of the study may have an explanatory power only for contexts similar to the one where the course was offered. 


\section{Findings}

The identified sources of prominent influences on the course are associated with three dominant discourses which guide the internationalisation of HEIs: liberal, critical and neoliberal (Andreotti et al., 2016; Pashby \& Andreotti, 2016). These tripartite set of discourses may not be neatly separated as a GCE curriculum may incorporate a blend of neo-liberal/liberal, liberal/critical or critical/neoliberal discourses, but they enable to disentangle the complexities around GCE and present findings in an accessible form.

\section{Liberal influences}

Liberal influences were not so prominent since the course was not focused on teaching the conventional ways of democratic participation. Instead, it was focused on teaching skills and strategies for creating change in accordance with a cosmopolitan human right perspective. Even though this approach differs from traditional-liberal civic education, it still aims to improve the participation of young people. In relation to the promotion of liberal civic values, an interviewee stated the following:

I think active citizenship means different things to different people in practice. But it boils down to taking an active role in shaping the world - to think about how things could be better and do something about it. After all, that is what democracy ought to be about, everyone having an equal say in how we build our societies. Of course, the majority are either not equipped to participate, or too busy providing for themselves and their families in a vastly unequal world. Which is why citizenship education is such a great idea. Being an active citizen does not necessarily mean campaigning, although that is one way! It might mean joining a party or a movement, making sure to always cast an informed vote, and raising your children to be kind, generous, and active citizens themselves.

The interviewee highlights the significance of conventional ways of participation based on a grounded notion of citizenship. She conceives citizenship as having a say in the making of collective decisions that affect all in society. From this angle, she concludes 
that the course was useful as people do not find enough time to learn citizenship. There are also critical discourses embedded in mostly liberal perspectives of the interviewee as evidence by her statements like 'having an equal say' and 'a vastly unequal world'. The interviewee views citizenship as a way of fighting inequalities and does not confine it to public civic spaces by underlining that even raising a child might include a dimension of education for active citizenship.

Liberal influences are evident in that the course capitalised on the diverse population of the university as an asset to promote intercultural dialogue as a way of cultivating GC. In fact, the promotion of intergroup interaction is recognised as an effective way of teaching GC (Caruana, 2014; Denson \& Bowman, 2013; McCowan, 2012). On that ground, group work was considered an integral part of student learning experiences. A student reflected on her group work experience as follows:

Well, group work is a general skill of course but I improved my teamwork and of course my general communication skills and I think overall... I gained some more confidence in myself, for example, speaking in public.

It seems the group work boasted the student's confidence in public speaking and made her feel safe to share her ideas and collaborate with others who she did not know beforehand. The experience of working with 'different' people is generally perceived as positive by students whose response highlighted the benefits of meeting new people, networking, collaborating with others on a project, hearing new perspectives, working with people of different expertise, degrees, backgrounds and people with a different mode of thinking. However, no student mentioned anything about their classmates' diverse identities because the question eliciting their response was formed in a way that did not demand such an answer. Nonetheless, students used the word 'different' in a broad sense which may encompass people's diverse identities. 
Few students were negative about their group work experience stating that the knowledge level of group members was uneven, and group members were too homogenous in terms of their degrees. Some found small group size as an issue stating that 'the small groups made it a bit discouraging at times'. One student suggested that it 'would be nice if you'd also work more in rotating groups'. In fact, rotating groups could have increased the chance to work with more students. However, this suggestion involves a breadth-depth dilemma, as rotating students would slim students' chance to develop meaningful relations. Another student commented that students could have been given 'an opportunity to present halfway through to other students on the strand'. In fact, this suggestion could improve the level of interaction within the cohort.

\section{Critical influences}

Given that the placement NGOs were campaigning on various issues of inequalities in the wider society, critical discourses largely came into the picture from that component of the course. For example, an NGO campaigning for the rights of LGBT-Q people in the Middle East was amongst the placement organisations, and it organised a workshop at the university. That critical dimension of the course that exemplifies the incorporation of marginalised voices was very much appreciated by the students. Students were generally positive about their experience associated with the NGOs. In the course evaluation surveys, 80.6 per cent of all 124 students stated that NGO placement helped them learn how to campaign, and 90.2 per cent of them found NGO staff supportive and helpful. Many students underlined that their motivation to take the course was the prospect of working with an NGO:

When I found out I could have a small place in Amnesty International I decided to do that because it could be a great experience, because I had never entered an 
NGO, so this was my main motivation, eeer, to find out more about the world of Amnesty International.

I think the biggest thing that I expect I would learn was real practical skills of actually putting together a campaign and seeing real-life examples

I particularly chose active citizenship due to my interest in campaigning and international development. It was a great decision.

These statements suggest that the course met students' expectations to work with an NGO and learn practical skills. In this regard, the NGOs' contributions improved the quality of the course, without which student expectations may be impossible to satisfy. The high level of student satisfaction suggests that critical discourses about inequalities, campaigning and raising awareness about a socio-political issue and real-life experience of citizenship have a great potential to improve the quality of GCE in universities. A student mounted a strong criticism that the course was not sufficiently inclusive of critical discourses:

The conception of global citizenship has been quite surface level, does not deal with the actual complexity of the concept. It has provided a critical citizenship conception by the teaching of issues of inequalities. However, the perspective taken was from the global North -would not say it has facilitated global values.

The interviewee's criticism is in line with the studies proposing that the incorporation of minority, marginal and disadvantaged voices can make an outstanding improvement in the quality of GCE (Clifford \& Montgomery, 2017; Rudolph, Sriprakash, \& Gerrard, 2018; Wrigley, 2018). For the interviewee, the course content was dominated by western perspectives, which were possibly produced by the white elites of western universities, and the rhetorical-mention of the concept of GC did not change the course's western-centric content into a global outlook. When the NGO component is ignored, the course may be judged as completely dominated by Western-centric 
perspectives as critical issues of race, class, gender and socio-economic inequalities were not evident in the course content and outcomes. For example, the course paid lip service to the issue of Islamophobia even though that issue was very much present in the lives of students. It could have addressed more anti-immigrant and anti-Muslim discourses, and an organisation campaigning on these issues could have been included amongst the placement organisations.

Finally, when attributions to human rights are seen as part of the critical discourses of GC, one may conclude that the course was strong in relying on human rights perspectives. However, it must not be forgotten that citizenship rights 'enhance social solidarity among selected individuals in the face of continued inequality' and human rights 'provide basic protections against arbitrariness' (Shafir, 2004, p. 14). Neither of these concepts plays an equalising role in the unequal socio-economic conditions and unequal access to power. They encourage to struggle for making what is socially unbearable for disadvantaged people bearable, which is needed for the reproduction of social order with its inequalities in it.

\section{Neoliberal influences}

Neoliberal discourses were prominent in many components of the course. For example, the university webpage promoted the course in the following way: 'Solve problems through innovation and entrepreneurship' and 'Get ready for your career and improve your CV' (UCL, 2018b). This neoliberal consideration of GCE is embraced by some students who considered the NGO experience as a way of strengthening their CVs and their prospect of finding a good job after graduation. They took the course with this motivation of gaining an economic reward, and it seems their neoliberal consideration of GCE was not effectively challenged by the course since they continued to voice neoliberal discourses in the post-course surveys. 
In relation to neoliberal influences, one of the most recurring findings is that, students felt a greater sense of agency and empowerment after taking the course. This increased sense of agency is shown in that students in the 2016 and 2017 cohorts rated 8.5 the $1-10$ scaled item 'I would describe myself as a global citizen'. In response to the 1-10 scaled item 'I know how to work with others to bring about change locally, nationally and globally', students rated themselves 8.1 out of 10 . In 2018, a newlyintroduced item 'I know several ways in which I can make a difference to some of the world's most challenging problems' is rated 4.4 out of 5 . The average of the same cohort on the item 'I feel able to operate in social and work settings anywhere in the world' is 4.3 out of 5 . These descriptive statistics, combined with the qualitative reflections, strongly indicate that students who took the course regarded themselves as global citizens and became more aware of their own agency:

It made me understand better how I can make a change in the world, to be able to stand up for what you think is right, be more caring and kinder towards people as we do not know what they are facing in life...

It has made me realise the different ways of being a global citizen, and the power we have as individuals to enact change globally.

Deepened my understanding of responsibility to each other and how one can go about making a change in the face of injustice

However, students arguably developed a simplified and overblown notion of GC as they seem too much focused on their individual agency and overlook the importance of communal and contextual dimensions of citizenship. Student statements do not include the term collective action, protest and public demonstrations as a way of bringing about change, but emphasise the vitality of their individual action. There is no clear sign that they recognise the significance of collective power and structures that perpetuate 
inequalities. The exaggeration of agency and individualised strategies of campaigning mask a crucial aspect of citizenship that rights are gained and maintained through collective struggles (Isin, 2017; Shafir \& Brysk, 2006). The avoidance to mention the term 'collective' is more acutely captured in the course description:

In our strand, we start from the position that citizenship is a feeling of responsibility for the wellbeing of others and the planet and an understanding that concerted action can help to change the world (UCL, 2017).

'Concerted action' is a timid way of highlighting the significance of collective action. The absence of the term collective in the course content and outcomes may be an effect of the prevalence of neoliberalism that promotes an 'individualistic conception of citizenship' (Biesta and Lawy 2006, p. 70). Or that dislike of collective actions may be unique to England's political culture as France differs from England in CE by listing protests as a form of citizenship act in its curriculum (Osler \& Starkey, 2009).

The avoidance to mention 'collective' and overemphasis on individual-centric campaigning strategies seem to have caused students to conceptualise citizenship in a superficial manner. For example, students did not mention any personal link to the socio-public issues they were interested in:

To find how I can most effectively and usefully contribute to the development and international projects

Global nature of the programme and ambition to be part of a community that can make a difference in the world by advocacy and development and overcoming inequality.

I felt that I really lacked general knowledge especially about things happening in different parts of the world and I think this programme really helped me be knowledgeable about the world and its people. 
Our film was about how the EU treats LGBTQ+ asylum seekers from North Africa, where it is often illegal to have homosexual relations. We wanted our viewers to become better informed about the situation for these people and see that we need to push our representatives to put humane and compassionate policies into place.

In the students' statements, citizenship turns into a concept expressing attempts and concerns to solve the problems of 'other people' living elsewhere on the planet. Without developing a well-defined position, students show an interest in 'global issues' with a view to contributing to the betterment of collective conditions of the global society. The sole focus on the 'global' and 'others' may play a disempowering and disheartening role and runs the risk of reducing citizenship to a form of charity-like altruism. The Ancient Greeks used citizenship to express the acts of free people to improve public good in contrast to idiocy, which they defined as an obsession with personal interests (Parker, 2003). Nevertheless, conceiving GC with no identifiable impact in our lives seems to hollow out the meaning of citizenship. In this way, it becomes a detached concept, an exotic hobby, or an entertaining activity exercised from one's comfort zone. It is hypocritical to console ourselves that signing a petition or shooting a film about a right issue is sufficient to fulfil our GC responsibility. GC requires personal dedication and consistent struggle in solidarity with others in the face of global injustices, which may start after recognising the negative implications of global issues in our own lives.

\section{Discussion and conclusions}

Students' appreciation of learning practical campaigning skills and gaining NGO work experience strongly suggest that citizenship courses at higher education level should incorporate more practical dimension and be led by those who are deeply engaged in the practicalities of citizenship. Universities may even outsource GCE courses to NGOs and 
appoint suitable academics as consultants to monitor the process. Studies exploring the effectiveness of university-level CE found that the combination of theoretical knowledge with opportunities to practise citizenship is effective to change students' understanding of citizenship and make them more engaged in socio-political issues (Harris, 2010; Papadiamantaki, 2014). The present study's findings are consistent with these studies that practical experience is essential for an effective GCE at HEIs.

In relation to the structural/intercultural scaffold, developed by Shultz (2011), the course seems to lack both structural and intercultural strength. The course was not strong structurally because it did not sufficiently address citizenship issues in students' own context (e.g. Islamophobia, rough sleeping). The course did not have intercultural strength because the course content reflected an instrumental approach to intercultural encounter. Even though there were students who valued interacting with others as intrinsically-valuable experience, some students considered it instrumental to an economic benefit, and the course did not challenge that way of considering 'other'.

The analysis suggests that the current neoliberal context of HEIs makes it highly difficult, if not impossible, to keep GCE curricula impervious to neo-liberal discourses. After finding out the GCE programmes in two universities in UK and Japan show an explicit concern for employability, Hammond \& Keating (2018) questioned the underlying intention as to whether the programmes aimed to educate 'global citizens or global workers' (p. 918). The present research confirms that the GCE programme in question was remarkably influenced by neoliberal discourses. The corrosive neoliberal influences can be hardly dispelled unless HEIs are recognised as a public good. Substantial improvements can be made once students and academics are assured to work freely for the benefit of the whole society rather than the interests of powerful elites. In this respect, this study calls for a more informed approach to citizenship 
curriculum development. It underlines that the alternative form of GCE can be strengthened by recognising the importance of collective action and political and contextual aspects of citizenship. To that end, GCE in HEIs should recognise citizenship as a deeply socio-political and communal endeavour. It should appreciate the vitality of collective struggles, rely on human rights perspectives and give young people opportunities to engage in citizenship practices in real-life contexts.

\section{Acknowledgements}

I would like to record my sincere thanks to anonymous reviewers of the journal and the members of the teaching team: Prof Hugh Starkey, Dr Ke Lin, Dr Ioanna Noula and Dr Mai Abu Moghli for their valuable support at various stages of this research.

\section{References}

Andreotti, V. de O. (2011). The political economy of global citizenship education. Globalisation, Societies and Education, 9(3-4), 307-310. https://doi.org/10.1080/14767724.2011.602292

Andreotti, V. de O., Stein, S., Pashby, K., \& Nicolson, M. (2016). Social cartographies as performative devices in research on higher education. Higher Education Research \& Development, 35(1), 84-99. https://doi.org/10.1080/07294360.2015.1125857

Apple, M. W. (2006). Educating the 'right' way: Markets, standards, God, and inequality (2. ed). New York: Routledge.

Banks, J. A. (2011). Educating citizens in diverse societies. Intercultural Education, 22(4), 243-251. https://doi.org/10.1080/14675986.2011.617417

Biesta, G. J. J. (2011). Learning democracy in school and society: Education, lifelong learning, and the politics of citizenship. Rotterdam: Sense Publ. 
Brydon-Miller, M., Greenwood, D., \& Maguire, P. (2003). Why action research? Action Research, 1(1), 9-28.

Camicia, S. P., \& Franklin, B. M. (2011). What type of global community and citizenship? Tangled discourses of neoliberalism and critical democracy in curriculum and its reform. Globalisation, Societies and Education, 9(3-4), 311322. https://doi.org/10.1080/14767724.2011.605303

Caruana, V. (2014). Re-thinking global citizenship in higher education: From cosmopolitanism and international mobility to cosmopolitanisation, resilience and resilient thinking. Higher Education Quarterly, 68(1), 85-104. https://doi.org/10.1111/hequ.12030

Clifford, V., \& Montgomery, C. (2014). Challenging conceptions of western higher education and promoting graduates as global citizens: Promoting graduates as global citizens. Higher Education Quarterly, 68(1), 28-45.

https://doi.org/10.1111/hequ.12029

Clifford, V., \& Montgomery, C. (2017). Designing an internationationalised curriculum for higher education: Embracing the local and the global citizen. Higher Education Research \& Development, 36(6), 1138-1151. https://doi.org/10.1080/07294360.2017.1296413

Denson, N., \& Bowman, N. (2013). University diversity and preparation for a global society: The role of diversity in shaping intergroup attitudes and civic outcomes. Studies in Higher Education, 38(4), 555-570. https://doi.org/10.1080/03075079.2011.584971

Fairclough, N. (2010). Analysing discourse: Textual analysis for social research. London: Routledge. 
Giroux, H. A. (2002). Neoliberalism, corporate culture and the promise of higher education. Harvard Educational Review, 72(4), 425-463.

Giroux, H. A. (2014). Neoliberalism's war on higher education. Illinois: Haymarket Books.

Green, W. (2018). Engaging "students as partners” in global learning: Some possibilities and provocations. Journal of Studies in International Education, 102831531881426. https://doi.org/10.1177/1028315318814266

Hammond, C. D., \& Keating, A. (2018). Global citizens or global workers? Comparing university programmes for global citizenship education in Japan and the UK. Compare: A Journal of Comparative and International Education, 48(6), 915934. https://doi.org/10.1080/03057925.2017.1369393

Harris, C. (2010). Active democratic citizenship and service-learning in the postgraduate classroom. Journal of Political Science Education, 6(3), 227-243. https://doi.org/10.1080/15512169.2010.494475

Harvey, D. (2005). A brief history of neoliberalism. Oxford: Oxford University Press.

Horey, D., Fortune, T., Nicolacopoulos, T., Kashima, E., \& Mathisen, B. (2018). Global Citizenship and Higher Education: A Scoping Review of the Empirical Evidence. Journal of Studies in International Education, 22(5), 472-492. https://doi.org/10.1177/1028315318786443

Isin, E. F. (2017). Performative citizenship. In A. Shachar, R. Bauböck, I. Bloemraad, \& M. Vink (Eds.), Oxford Handbook of Citizenship. Retrieved from http://enginfisin.net/assets/isin-2017-b.pdf

Johnson, L., \& Morris, P. (2012). Critical citizenship education in England and France: A comparative analysis. Comparative Education, 48(3), 283-301. https://doi.org/10.1080/03050068.2011.588885 
Krippendorff, K. (2004). Content analysis: An introduction to its methodology (2nd ed). Thousand Oaks: Sage.

Leask, B. (2015). Internationalizing the curriculum. New York: Routledge.

Li, Z. (2017). Citizenship education 'goes global': Extra-curricular learning in an overseas campus of a British civic university. International Journal of Lifelong Education, 36(6), 662-678. https://doi.org/10.1080/02601370.2017.1375565

Marginson, S. (2014). Higher education as a public good in a marketized east asian environment. In A. Yonezawa, Y. Kitamura, A. Meerman, \& K. Kuroda (Eds.), Emerging International Dimensions in East Asian Higher Education (pp. 1533). https://doi.org/10.1007/978-94-017-8822-9_2

Marshall, H. (2011). Instrumentalism, ideals and imaginaries: Theorising the contested space of global citizenship education in schools. Globalisation, Societies and Education, 9(3-4), 411-426. https://doi.org/10.1080/14767724.2011.605325

McChesney, R. W. (1999). Introduction. In N. Chomsky, Profit over people: Neoliberalism and global order (pp. 7-16). New York: Seven Stories Press. McCowan, T. (2012). Opening spaces for citizenship in higher education: Three initiatives in English universities. Studies in Higher Education, 37(1), 51-67. https://doi.org/10.1080/03075079.2010.493934

McLaughlin, T. H. (1992). Citizenship, diversity and education: A philosophical perspective. Journal of Moral Education, 21(3), 235-250. https://doi.org/10.1080/0305724920210307

Merriam, S. B. (2009). Qualitative research: A guide to design and implementation. San Francisco: Jossey-Bass. 
Olssen, M. (1996). In defence of the welfare state and publicly provided education: A New Zealand perspective. Journal of Education Policy, 11(3), 337-362. https://doi.org/10.1080/0268093960110305

Osler, A., \& Starkey, H. (2003). Learning for cosmopolitan citizenship: Theoretical debates and young people's experiences. Educational Review, 55(3), 243-254. https://doi.org/10.1080/0013191032000118901

Osler, A., \& Starkey, H. (2009). Citizenship education in France and England: Contrasting approaches to national identity and diversity. In J. A. Banks (Ed.), The Routledge International Companion to Multicultural Education (pp. 334347). New York: Routledge.

Oxley, L., \& Morris, P. (2013). Global citizenship: A typology for distinguishing its multiple conceptions. British Journal of Educational Studies, 61(3), 301-325. https://doi.org/10.1080/00071005.2013.798393

Papadiamantaki, Y. (2014). Active citizenship in university education: Lessons learnt in times of crisis. Journal of Social Science Education, 13(4), 90-97. https://doi.org/10.2390/jsse-v13-i3-1358

Parker, W. C. (2003). Teaching democracy. New York: Teacher's College Press.

Pashby, K., \& Andreotti, V. de O. (2016). Ethical internationalisation in higher education: Interfaces with international development and sustainability. Environmental Education Research, 22(6), 771-787. https://doi.org/10.1080/13504622.2016.1201789

Rizvi, F. (2009). Towards cosmopolitan learning. Discourse: Studies in the Cultural Politics of Education, 30(3), 253-268. https://doi.org/10.1080/01596300903036863 
Rudolph, S., Sriprakash, A., \& Gerrard, J. (2018). Knowledge and racial violence: The shine and shadow of 'powerful knowledge'. Ethics and Education, 13(1), 22-38. https://doi.org/10.1080/17449642.2018.1428719

Shafir, G. (2004). Citizenship and human rights in an era of globalization. In A. Brysk \& G. Shafir (Eds.), People out of place: Globalization, human rights, and the citizenship gap (pp. 11-25). New York: Routledge.

Shafir, G., \& Brysk, A. (2006). The globalization of rights: From citizenship to human rights. Citizenship Studies, 10(3), 275-287.

https://doi.org/10.1080/13621020600772073

Shultz, L. (2007). Educating for global citizenship: Conflicting agendas and understandings. The Alberta Journal of Educational Research, 53(3), 248-258.

Shultz, L. (2011). Engaging the multiple discourses of global citizenship education within a Canadian university: Deliberation, contestation, and social justice possibilities. In L. Shultz, A. A. Abdi, \& G. H. Richardson (Eds.), Global citizenship education in post-secondary institutions (pp. 13-24). New York: Peter Lang.

UCL. (2017). Active Citizenship [Edu]. Retrieved 20 October 2019, from UCL Global Citizenship Programme website: https://www.ucl.ac.uk/global-citizenshipprogramme/right-strand-for-me/active-citizenship

UCL. (2018a). Key statistics [Edu]. Retrieved 27 November 2018, from About UCL website: https://www.ucl.ac.uk/about/what/key-statistics\#student-numbers

UCL. (2018b). Why get involved? [Edu]. Retrieved 27 November 2018, from UCL global citizenship programme website: https://www.ucl.ac.uk/global-citizenshipprogramme/why-get-involved 
Wrigley, T. (2018). 'Knowledge', curriculum and social justice. The Curriculum Journal, 29(1), 4-24. https://doi.org/10.1080/09585176.2017.1370381 